\title{
MLH1 expression predicts the response to preoperative therapy and is associated with PD-L1 expression in esophageal cancer
}

\author{
KOTA MOMOSE* , MAKOTO YAMASAKI*, KOJI TANAKA, YASUHIRO MIYAZAKI, \\ TOMOKI MAKINO, TSUYOSHI TAKAHASHI, YUKINORI KUROKAWA, KIYOKAZU NAKAJIMA, \\ SHUJI TAKIGUCHI, MASAKI MORI and YUICHIRO DOKI
}

Department of Gastroenterological Surgery, Graduate School of Medicine, Osaka University, Suita, Osaka 565-0871, Japan

Received October 31, 2016; Accepted March 3, 2017

DOI: $10.3892 / \mathrm{ol} .2017 .6215$

\begin{abstract}
Programmed death-ligand 1 (PD-1/PD-L1) inhibition therapy demonstrates potential as a future treatment for esophageal cancer. Mismatch repair status and tumor PD-L1 expression are the candidate predictive biomarkers for response to this therapy. In colorectal cancer, mismatch repair-deficient tumors are associated with improved survival, although they are not sensitive to 5-fluorouracil-based chemotherapy. The purpose of the present study was to investigate the association between MutL homolog 1 (MLH1) expression and prognosis, response to therapy and PD-L1 expression in esophageal cancer. Immunohistochemistry was used to evaluate MLH1 and PD-L1 expression in 251 resected specimens. Of the specimens, $30.3 \%$ exhibited low MLH1 expression and $15.5 \%$ exhibited high PD-L1 expression. The 5-year overall survival rates for the high MLH1 expression group and the low MLH1 expression group were 51.3 and $55.6 \%$, respectively $(\mathrm{P}=0.5260)$. The responder ratio was $45.7 \%$ in the high MLH1 expression group and $15.4 \%$ in the low MLH1 expression group $(\mathrm{P}<0.0001)$. The frequency of high PD-L1 expression was $11.4 \%$ in the high MLH1 expression group $(\mathrm{P}=0.0064)$ and $25.0 \%$ in the low MLH1 expression group. MLH1 expression may be a predictive factor for the response to preoperative therapy in esophageal cancer, and esophageal cancer with low MLH1 expression may have a mechanism that assists in promoting tumor PD-L1 expression.
\end{abstract}

\section{Introduction}

Esophageal cancer may be treated with three modalities, namely surgery, chemotherapy and radiotherapy (1-3). Recent advances in esophageal cancer treatment may be

Correspondence to: Dr Makoto Yamasaki, Department of Gastroenterological Surgery, Graduate School of Medicine, Osaka University, 2-2-E2 Yamadaoka, Suita, Osaka 565-0871, Japan

E-mail: myamasaki@gesurg.med.osaka-u.ac.jp

*Contributed equally

Key words: esophageal cancer, MutL homolog 1, programmed death-ligand 1, expression, response attributed to improvements in surgical techniques (4), perioperative management and chemotherapy $(5,6)$. Programmed death-ligand 1 (PD-1/PD-L1) inhibition therapy is currently emerging as a promising option $(7,8)$, and its clinical benefit has been suggested in esophageal cancer (9). This treatment has the potential to be a fourth modality for treating esophageal cancer in the future.

In general, immunotherapy may be effective for treating tumors harboring thousands of mutations. It is postulated that an increased number of mutation-associated neoantigens stimulate the host immune system. In fact, Le et al (10) demonstrated that mismatch repair (MMR)-deficient tumors are more responsive to PD-1 blockade compared with MMR-proficient tumors, possibly as MMR deficiency results in a higher rate of point mutation. Therefore, MMR status may be a predictive factor for the response to PD-1/PD-L1 inhibition therapy (10).

PD-L1 expression is a way for tumors to evade the immune system. Thus, tumor PD-L1 expression may be used as a predictive biomarker for the response to PD-1/PD-L1 inhibition therapy, as suggested previously (11). In this scenario, the MMR-deficient tumor, which exhibits enhanced antigenicity as the result of a high rate of mutation, may have a mechanism that increases PD-L1 expression and thereby assists the tumor in evading the immune system. However, little is known about the association between MMR status and PD-L1 expression in esophageal cancer.

MMR-deficient cancer arises from an inherited mutation in an MMR gene or by epigenetic suppression of MMR gene expression (12). In esophageal cancer, hypermethylation of the MLH1 promoter appears to be involved in MMR deficiency (13). In colorectal cancer, MMR-deficient tumors are associated with improved survival $(14,15)$, although they are not sensitive to 5-fluorouracil (5-FU)-based chemotherapy $(12,16,17)$. These characteristics have not been validated adequately in esophageal cancer. The purpose of the present study was to investigate the association between MLH1 expression and prognosis, response to therapy and PD-L1 expression in esophageal cancer.

\section{Patients and methods}

Study population. Of the patients who underwent esophagectomy in Osaka University Hospital (Suita, Osaka, Japan) 
between August 2000 and January 2013, 251 patients met the following criteria and were included in this analysis: i) R0 resection was performed; ii) written informed consent was obtained; iii) surgical specimens were available for analysis; and iv) for cases with preoperative therapy, remaining cancer tissue was detected microscopically. The Union for International Cancer Control Tumor-Node-Metastasis classification (7th edition) was used for staging (18). The present study was approved by the Institutional Review Board of Osaka University Hospital.

Treatment protocol. The basic strategy for esophageal cancer treatment was as follows: Chemoradiotherapy, described previously (19), as the initial treatment for patients with cT4 cancer, and surgical resection was performed in patients who received an initial and then a revised diagnosis of disease exhibiting the cancer invasion of adjacent organs. Preoperative chemotherapy followed by surgery was indicated for patients with $\mathrm{cN} 1$ and/or cM1lym with cT1-3 tumors. Surgery was indicated for patients with cT1-3N0 tumors without preoperative treatment between January 2005 and January 2009; subsequent to January 2009, preoperative chemotherapy followed by surgery was indicated for patients with cT2-3N0 tumors. Surgery was performed 4-8 weeks after preoperative chemotherapy.

Postoperative follow-up evaluations were performed every 3-4 months for the first 2 years and every 6 months thereafter by computed tomography scanning plus annual endoscopy for 5 years.

Evaluation of the histological response to preoperative therapy. The histological response to preoperative therapy was evaluated using the proportion of viable cancer cells according to the Japanese Society for Esophageal Diseases criteria $(20,21)$ : Grade 0, no histological effect; grade 1a, viable cancer cells accounted for more than two-thirds of the tumor tissue; grade $1 b$, viable cancer cells accounted for between one-third and two-thirds of the tumor tissue; grade 2, viable cancer cells account for less than one-third of the tumor tissue; and grade 3, no residual viable cancer cells. Grade 3 samples were excluded from the present study as aforementioned. Patients with grade 0 or la disease were defined as non-responders and those with grade $1 \mathrm{~b}$ or 2 disease as responders.

MLH1 immunohistochemistry. Tissue sections measuring $3.5-\mu \mathrm{m}$ thick were prepared from formalin-fixed, paraffin-embedded (FFPE) blocks. The tissue slides were deparaffinized in xylene and then rehydrated through graded ethanol solutions. For antigen retrieval, the slides were incubated in $10 \mathrm{mM}$ citrate buffer $(\mathrm{pH} 6.0)$ at $110^{\circ} \mathrm{C}$ for $20 \mathrm{~min}$. Endogenous peroxidase activity was blocked by incubation in $0.3 \%$ hydrogen peroxide for $20 \mathrm{~min}$ at room temperature. The slides were then incubated overnight with the specific primary antibody, a mouse anti-MLH1 monoclonal antibody (cat. no. 550838; clone G168-15; dilution, 1:100; BD Biosciences, Franklin Lakes, NJ, USA) at $4^{\circ} \mathrm{C}$ in a moist chamber. A negative control was prepared by omitting the primary antibody. Antibody binding was visualized using the ABC peroxidase detection system (Vector Laboratories, Burlingame, CA, USA). The slides were incubated in 3,3'-diaminobenzidine tetrahydrochloride (DAB) with
$0.05 \%$ hydrogen peroxide for $4.5 \mathrm{~min}$. Finally, the slides were counterstained with $0.1 \%$ hematoxylin for $30 \mathrm{sec}$. Normal human tonsil tissue from other patients was used as a positive control.

Interpreting MLH1 expression in cancer tissue. MLH1 expression was evaluated according to the intensity and frequency of positive nuclear-stained cancer cells as described previously (22). The staining intensity of each cancer cell was compared with that of normal epithelium or the positive control. No staining or weaker intensity staining was defined as negative staining. The same or stronger intensity staining was defined as positive staining. Specimens containing $>50 \%$ positive cancer cells were classified as high MLH1 expression specimens, and those containing $\leq 50 \%$ positive cancer cells were classified as low MLH1 expression specimens. The frequency of the positively stained cells was assessed throughout the entire section using an optical microscope at x20 magnification. The immunohistochemical staining was independently evaluated by two of the authors who were blinded to the clinical data.

PD-L1 immunohistochemistry. Tissue sections measuring $3.5-\mu \mathrm{m}$ thick were prepared from FFPE blocks. The sections were deparaffinized in xylene and then rehydrated through graded ethanol solutions. For antigen retrieval, the slides were incubated in $10 \mathrm{mM}$ citrate buffer $(\mathrm{pH} 6.5)$ at $110^{\circ} \mathrm{C}$ for $10 \mathrm{~min}$. Endogenous peroxidase activity was blocked by incubation in $0.3 \%$ hydrogen peroxide for $20 \mathrm{~min}$ at room temperature. The slides were then incubated for $1 \mathrm{~h}$ with the specific primary antibody, a rabbit anti-PD-L1 monoclonal antibody (cat. no. M4424; clone SP142; dilution, 1:100; Spring Bioscience, Pleasanton, CA, USA) at $4^{\circ} \mathrm{C}$ in a moist chamber. A negative control was prepared by omitting the primary antibody. Antibody binding was visualized using the ABC peroxidase detection system (Vector Laboratories). The slides were incubated in DAB with $0.05 \%$ hydrogen peroxide for $2.5 \mathrm{~min}$. Finally, the slides were counterstained with $0.1 \%$ hematoxylin for $30 \mathrm{sec}$. Normal human placenta tissue from other patients was used as a positive control.02.

Interpreting PD-L1 expression in cancer tissue. PD-L1 expression was evaluated according to the frequency of positive membrane-stained tumor cells (TCs) and tumor-infiltrating immune cells (ICs), as described previously (23). Specimens were considered to have low PD-L1 expression if $<5 \%$ of the cells were stained, and were considered to have high PD-L1 expression if $\geq 5 \%$ of the cells were stained. The frequency of positively stained cells was assessed throughout the entire section using an optical microscope at x20 magnification. Hematoxylin and eosin staining of the serial section of the FFPE tissue was used to detect ICs. The immunohistochemical staining was independently evaluated by two of the authors who were blinded to the clinical data.

Statistical analysis. Continuous variables were expressed as the mean \pm standard deviation, and their associations with PD-L1 or MLH1 expression were assessed using unpaired Student's t-tests. The associations between categorical variables and PD-L1 or MLH1 expression were assessed using 
Table I. Clinicopathological characteristics of the study population according to MLH1 expression.

\begin{tabular}{|c|c|c|c|c|}
\hline \multirow[b]{2}{*}{ Characteristic } & \multirow[b]{2}{*}{ Total } & \multicolumn{2}{|c|}{ MLH1 expression } & \multirow[b]{2}{*}{ P-value } \\
\hline & & High & Low & \\
\hline All patients, n (\%) & 251 & $175(69.7)$ & $76(30.3)$ & \\
\hline Sex, n (\%) & & & & 0.6820 \\
\hline Male & 218 & $153(70.2)$ & 65 (29.8) & \\
\hline Female & 33 & $22(66.7)$ & $11(33.3)$ & \\
\hline Age, years ${ }^{\mathrm{a}}$ & $65.8 \pm 9.1$ & $65.9 \pm 9.7$ & $65.3 \pm 7.6$ & 0.6325 \\
\hline Tumor location, $\mathrm{n}(\%)$ & & & & 0.2802 \\
\hline Upper & 50 & $38(76.0)$ & $12(24.0)$ & \\
\hline Middle & 124 & 87 (70.2) & 37 (29.8) & \\
\hline Lower & 77 & $50(64.9)$ & $27(35.1)$ & \\
\hline Tumor histology, n (\%) & & & & 0.4626 \\
\hline Squamous cell carcinoma & 245 & $170(69.4)$ & $75(30.6)$ & \\
\hline Adenocarcinoma & 6 & $5(83.3)$ & $1(16.7)$ & \\
\hline Preoperative therapy, n (\%) & & & & 0.1713 \\
\hline+ & 209 & $142(67.9)$ & $67(32.1)$ & \\
\hline- & 42 & $33(78.6)$ & $9(21.4)$ & \\
\hline Pathological depth of invasion, $\mathrm{n}(\%)$ & & & & 0.0228 \\
\hline pT1 & 62 & $51(82.3)$ & $11(17.7)$ & \\
\hline pT2 & 56 & $41(73.2)$ & $15(26.8)$ & \\
\hline pT3 & 128 & $81(63.3)$ & $47(36.7)$ & \\
\hline pT4 & 5 & $2(40.0)$ & $3(60.0)$ & \\
\hline Pathological lymph node metastasis, $\mathrm{n}(\%)$ & & & & 0.3494 \\
\hline pNo & 88 & $67(76.1)$ & $21(23.9)$ & \\
\hline $\mathrm{pN} 1$ & 95 & $65(68.4)$ & $30(31.6)$ & \\
\hline $\mathrm{pN} 2$ & 48 & $31(64.6)$ & $17(35.4)$ & \\
\hline $\mathrm{pN} 3$ & 20 & $12(60.0)$ & $8(40.0)$ & \\
\hline Pathological stage, n (\%) & & & & 0.0553 \\
\hline I & 56 & $47(83.9)$ & $9(16.1)$ & \\
\hline II & 61 & $42(68.9)$ & $19(31.1)$ & \\
\hline III & 101 & $66(65.3)$ & $35(34.7)$ & \\
\hline IV & 33 & $20(60.6)$ & $13(39.4)$ & \\
\hline
\end{tabular}

${ }^{\mathrm{a}}$ Mean \pm standard deviation. MLH1, MutL Homolog 1.

Pearson's $\chi^{2}$ test. Overall survival (OS) was defined as the elapsed time from the date of surgery to the date of mortality or last follow-up, and was calculated using the Kaplan-Meier method, while the log-rank test was used for comparisons. $\mathrm{P}<0.05$ was considered to indicate a statistically significant difference. All statistical analyses were performed using JMP Pro ${ }^{\circledR} 11$ software (SAS Institute Inc., Cary, NC, USA).

\section{Results}

Patient characteristics. The clinicopathological characteristics of the study population are summarized in Table I. The tumor location was the upper esophagus in 50 patients (19.9\%), the middle esophagus in 124 patients (49.4\%) and the lower esophagus in 77 patients $(30.7 \%)$. Tumor histology was squamous cell carcinoma in 245 patients $(97.6 \%)$. A total of 209 patients $(83.3 \%)$ underwent preoperative therapy, i.e., chemotherapy alone or concomitant chemoradiotherapy. There were 62 pT1 patients (24.7\%), 56 pT2 patients (22.3\%), 128 pT3 patients $(51.0 \%)$, and 5 pT4 patients $(2.0 \%)$. There were 88 pN0 patients (35.1\%), $95 \mathrm{pN} 1$ patients $(37.8 \%), 48 \mathrm{pN} 2$ patients $(19.1 \%)$ and $20 \mathrm{pN} 3$ patients $(8.0 \%)$. The median follow-up period for the surviving cases was 53.7 months.

MLH1 immunohistochemical staining and patient characteristics. Representative MLH1 immunohistochemical staining is illustrated in Fig. 1. Cancer cells typically exhibited nuclear MLH1 immunohistochemical staining, as suggested previously (20). In certain patients, the intensity of the stained cells was not homogeneous. Specifically, cancer cells on the inner side of the tumor tissue tended to exhibit weaker staining, while cancer cells at the surface of the tumor tissue tended to 

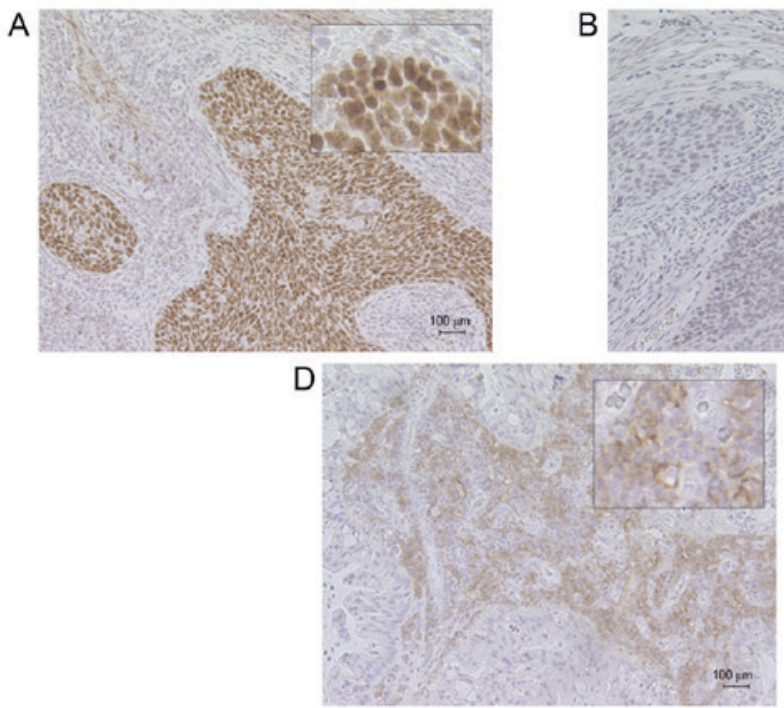

B

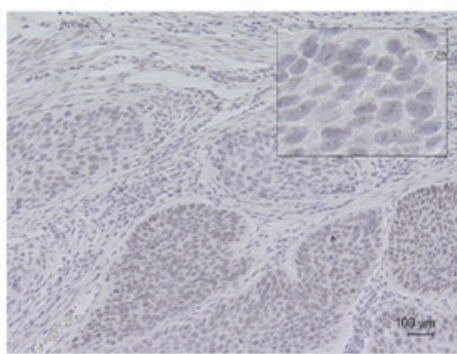

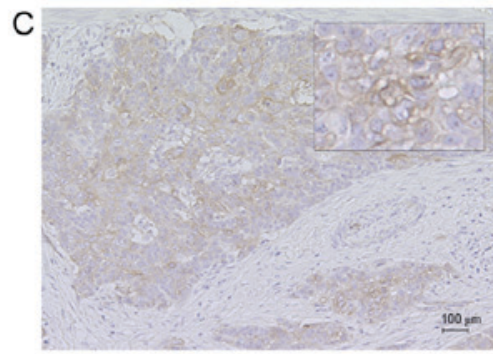

$\mathrm{E}$

Figure 1. Representative immunohistochemical stain of MLH1 and PD-L1 in esophageal cancer tissue at x100 magnification. (A) High MLH1 expression; (B) low MLH1 expression; (C) high PD-L1 expression in TCs; (D) high PD-L1 expression in ICs; (E) low PD-L1 expression in TCs and ICs. MLH1, MutL homolog 1; PD-L1, programmed death-ligand 1; TCs, tumor cells; ICs, tumor-infiltrating immune cells.

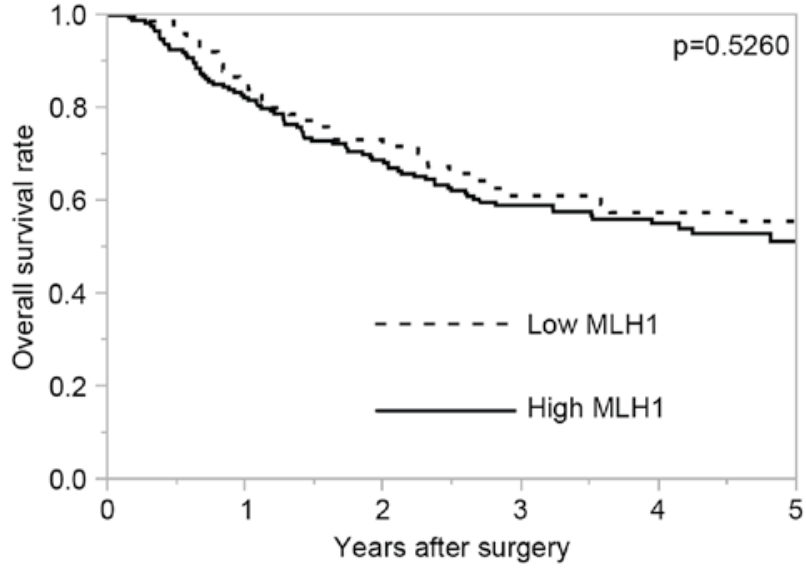

Figure 2. Overall survival of the study population according to MLH1 expression. MutL homolog 1 .

exhibit stronger staining. Low MLH1 expression was identified in $30.3 \%$ of the specimens.

Table I summarizes the clinicopathological characteristics in the study population according to MLH1 expression. There were no statistically significant differences in terms of sex, tumor location, tumor histology or pathological stage according to MLH1 expression.

Table II summarizes the histological responses according to MLH1 expression for patients who underwent preoperative therapy. The ratio of responders was higher in the high MLH1 expression group compared with the low MLH1 expression group $(\mathrm{P}<0.0001)$.

PD-L1 immunohistochemical staining and patient characteristics. Fig. 1 demonstrates representative immunohistochemical staining of PD-L1. Cancer cells exhibited PD-L1 immunohistochemical staining of the basal membranes. The distribution of PD-L1-positive cancer cells was very focalized, and PD-L1-positive cells were commonly observed at the interface between cancer cells and the stroma with ICs, as previously identified (23). ICs also exhibited a membranous PD-L1 staining pattern, with PD-L1-positive ICs typically observed toward the periphery of the tumor. It was revealed that $15.5 \%$ of the study population exhibited high PD-L1 expression in TCs, and $23.5 \%$ exhibited high PD-L1 expression in ICs. A total of 189 cases (75.3\%) demonstrated correspondence between PD-L1 expression in TCs and ICs.

There were no statistically significant differences in the clinicopathological characteristics according to PD-L1 expression in ICs and TCs, with the exception of age (Table III).

For the patients who underwent preoperative therapy, the ratio of responders to non-responders did not differ according to PD-L1 expression (Table IV).

Correlation between PD-LI expression and MLHI expression. PD-L1 expression according to MLH1 expression is illustrated in Table V. With regard to TCs, $25.0 \%$ of the low MLH1 expression group exhibited high PD-L1 expression, as did $11.4 \%$ of the high MLH1 expression group. The frequency of high PD-L1 expression was significantly higher in the low MLH1 expression group compared with the high MLH1 expression group $(\mathrm{P}=0.0064)$. With regard to $\mathrm{ICs}, 17.1 \%$ of the low MLH1 expression group exhibited high PD-L1 expression, as did $26.3 \%$ of the high MLH1 expression group. There was no correlation between PD-L1 expression and MLH1 expression.

Survival analysis. Fig. 2 demonstrates the OS rate according to MLH1 expression. The 5-year OS rates in the high MLH1 expression group and the low MLH1 expression group were 51.3 and $55.6 \%$, respectively. There was no significant difference in OS according to MLH1 expression $(\mathrm{P}=0.5260)$. For patients without preoperative therapy $(n=42)$, the 5-year OS rates of the high and the low MLH1 expression groups were 60.4 and $77.8 \%$, respectively $(\mathrm{P}=0.4984)$. For patients with 
Table II. Histological response to preoperative therapy according to MLH1 expression in the cases with preoperative therapy.

\begin{tabular}{lccr}
\hline & & \multicolumn{2}{c}{ MLH1 expression ${ }^{\mathrm{a}}$} \\
\cline { 3 - 4 } Histological response to preoperative therapy & Total & High, n (\%) & Low, n (\%) \\
\hline Non-responder & 130 & $75(54.3)$ & $55(84.6)$ \\
Responder & 73 & $63(45.7)$ & $10(15.4)$ \\
\hline
\end{tabular}

${ }^{\mathrm{a}} \mathrm{P}<0.0001$ for comparison between high and low MLH1 expression; MLH1, MutL Homolog 1.

Table III. Clinicopathological characteristics of the study population according to PD-L1 expression.

\begin{tabular}{|c|c|c|c|c|c|c|c|}
\hline \multirow[b]{2}{*}{ Characteristic } & \multirow[b]{2}{*}{ Total } & \multicolumn{2}{|c|}{$\begin{array}{c}\text { PD-L1 } \\
\text { expression (TC) }\end{array}$} & \multirow[b]{2}{*}{$\mathrm{P}$-value } & \multicolumn{2}{|c|}{$\begin{array}{c}\text { PD-L1 } \\
\text { expression (IC) }\end{array}$} & \multirow[b]{2}{*}{ P-value } \\
\hline & & Low & High & & Low & High & \\
\hline Total, n (\%) & 251 & $212(84.5)$ & $39(15.5)$ & & $192(76.5)$ & $59(23.5)$ & \\
\hline Sex, n (\%) & & & & 0.3343 & & & 0.584 \\
\hline Male & 218 & $186(85.3)$ & $32(14.7)$ & & $168(77.1)$ & $50(22.9)$ & \\
\hline Female & 33 & $26(78.8)$ & $7(21.2)$ & & $24(72.7)$ & $9(27.3)$ & \\
\hline Age, years $^{\mathrm{a}}$ & $65.8 \pm 9.1$ & $65.6 \pm 9.2$ & $66.7 \pm 8.7$ & 0.5009 & $65.0 \pm 9.2$ & $68.4 \pm 8.5$ & 0.0122 \\
\hline Tumor location, n (\%) & & & & 0.1216 & & & 0.0324 \\
\hline Upper & 50 & $39(78.0)$ & $11(22.0)$ & & $33(66.0)$ & $17(34.0)$ & \\
\hline Middle & 124 & $103(83.1)$ & $21(16.9)$ & & $93(75.0)$ & $31(25.0)$ & \\
\hline Lower & 77 & $70(90.9)$ & $7(9.1)$ & & $66(85.7)$ & $11(14.3)$ & \\
\hline Tumor histology, n (\%) & & & & 0.2876 & & & 0.5656 \\
\hline Squamous cell carcinoma & 245 & $206(84.1)$ & $39(15.9)$ & & $188(76.7)$ & $57(23.3)$ & \\
\hline Adenocarcinoma & 6 & $6(100.0)$ & $0(0.0)$ & & $4(66.7)$ & $2(33.3)$ & \\
\hline Preoperative therapy, n (\%) & & & & 0.8061 & & & 0.653 \\
\hline+ & 209 & $176(84.2)$ & $33(15.8)$ & & $161(77.0)$ & $48(23.0)$ & \\
\hline- & 42 & $36(85.7)$ & $6(14.3)$ & & $31(73.8)$ & $11(26.2)$ & \\
\hline Pathological depth of invasion, $\mathrm{n}(\%)$ & & & & 0.6556 & & & 0.9875 \\
\hline pT1 & 62 & $51(82.3)$ & $11(17.7)$ & & $48(77.4)$ & $14(22.6)$ & \\
\hline pT2 & 56 & $49(87.5)$ & $7(12.5)$ & & $42(75.0)$ & $14(25.0)$ & \\
\hline pT3 & 128 & $107(83.6)$ & $21(16.4)$ & & $98(76.6)$ & $30(23.4)$ & \\
\hline pT4 & 5 & $5(100.0)$ & $0(0.0)$ & & $4(80.0)$ & $1(20.0)$ & \\
\hline Pathological lymph node metastasis, $\mathrm{n}(\%)$ & & & & 0.0997 & & & 0.2921 \\
\hline pNO & 88 & $78(88.6)$ & $10(11.4)$ & & $68(77.3)$ & $20(22.7)$ & \\
\hline $\mathrm{pN} 1$ & 95 & $79(83.2)$ & $16(16.8)$ & & $77(81.1)$ & $18(18.9)$ & \\
\hline $\mathrm{pN} 2$ & 48 & $36(75.0)$ & $12(25.0)$ & & $32(66.7)$ & $16(33.3)$ & \\
\hline $\mathrm{pN} 3$ & 20 & $19(95.0)$ & $1(5.0)$ & & $15(75.0)$ & $5(25.0)$ & \\
\hline Pathological stage, n (\%) & & & & 0.7029 & & & 0.1713 \\
\hline I & 56 & $48(85.7)$ & $8(14.3)$ & & $41(73.2)$ & $15(26.8)$ & \\
\hline II & 61 & $54(88.5)$ & $7(11.5)$ & & $53(86.9)$ & $8(13.1)$ & \\
\hline III & 101 & $83(82.2)$ & $18(17.8)$ & & $73(72.3)$ & $28(27.7)$ & \\
\hline IV & 33 & $27(81.8)$ & $6(18.2)$ & & $25(75.8)$ & $8(24.2)$ & \\
\hline
\end{tabular}

${ }^{\mathrm{a}}$ Mean \pm standard deviation. TC, tumor cell; IC, tumor-infiltrating immune cell; PD-L1, programmed death-ligand 1.

preoperative therapy $(\mathrm{n}=209)$, the 5 -year OS rates of the high and the low MLH1 expression groups were 49.4 and $52.7 \%$, respectively $(\mathrm{P}=0.5459)$.
OS was significantly poorer in patients with high PD-L1 expression compared with patients with low PD-L1 expression in TCs and ICs ( $\mathrm{P}=0.0207$ and $\mathrm{P}<0.0001$, respectively; Fig. 3). 
Table IV. Histological response to preoperative therapy in cases with preoperative therapy according to PD-L1 expression.

\begin{tabular}{|c|c|c|c|c|c|}
\hline \multirow{2}{*}{$\begin{array}{l}\text { Histological response to } \\
\text { preoperative therapy }\end{array}$} & \multirow[b]{2}{*}{ Total } & \multicolumn{2}{|c|}{ PD-L1 expression $(\mathrm{TC})^{\mathrm{a}}$} & \multicolumn{2}{|c|}{ PD-L1 expression (IC) ${ }^{\mathrm{b}}$} \\
\hline & & Low, n (\%) & High, n (\%) & Low, n (\%) & High, n (\%) \\
\hline Non-responder & 130 & 107 (62.2) & $23(74.2)$ & $97(62.2)$ & $33(68.8)$ \\
\hline Responder & 73 & $65(37.8)$ & $8(25.8)$ & $59(37.8)$ & $14(29.2)$ \\
\hline
\end{tabular}

${ }^{\mathrm{a}} \mathrm{P}=0.2006$ for the comparison between TC high and low PD-L1 expression; ${ }^{\mathrm{b}} \mathrm{P}=0.3144$, for the comparison between IC high and low PD-L1 expression; TC, tumor cell; IC, tumor-infiltrating immune cell; PD-L1, programmed death-ligand 1.

Table V. Correlation between MLH1 expression and PD-L1 expression in esophageal cancer tissue.

\begin{tabular}{|c|c|c|c|c|c|c|}
\hline \multirow[b]{2}{*}{ Expression } & \multicolumn{3}{|c|}{ PD-L1 expression (TC) } & \multicolumn{3}{|c|}{ PD-L1 expression (IC) } \\
\hline & Low & High & P-value & Low & High & P-value \\
\hline MLH1 expression & & & $\mathrm{P}=0.0064$ & & & $\mathrm{P}=0.1150$ \\
\hline High, n (\%) & $155(88.6)$ & $20(11.4)$ & & $129(73.7)$ & $46(26.3)$ & \\
\hline Low, n (\%) & $57(75.0)$ & $19(25.0)$ & & 63 (82.9) & $13(17.1)$ & \\
\hline
\end{tabular}

$\mathrm{P}=0.1150$ for the comparison between low and high MLH1 expression. TC, tumor cell; IC, tumor-infiltrating immune cell; PD-L1, programmed death-ligand 1; MLH1, MutL Homolog 1.
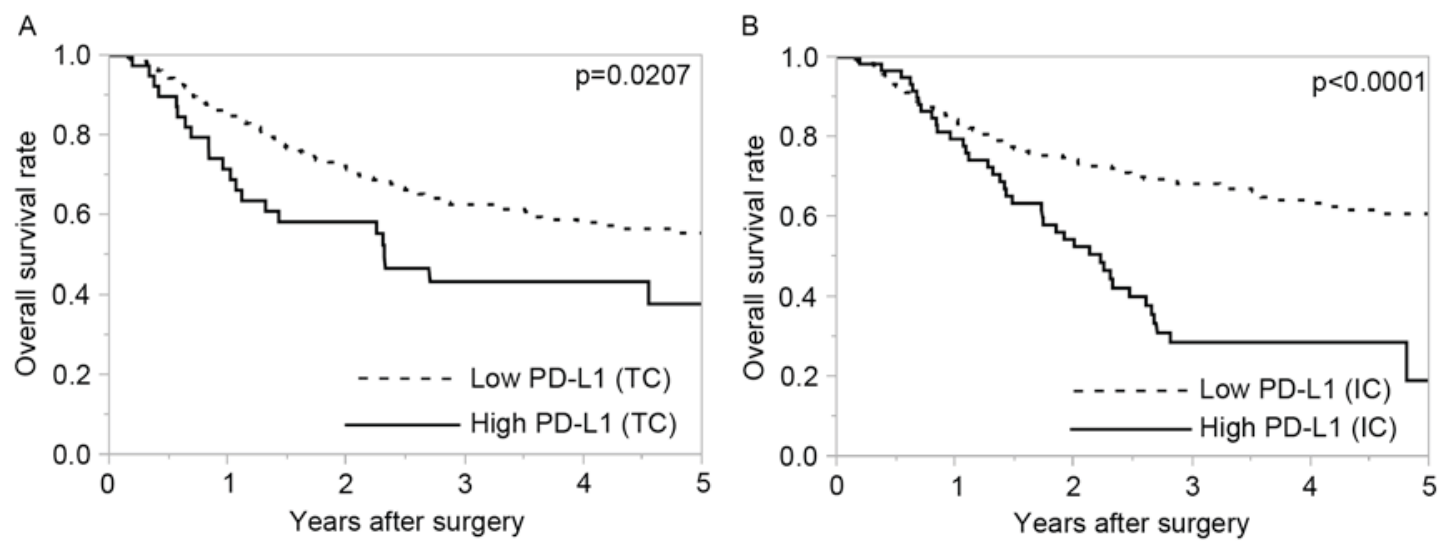

Figure 3. Overall survival of the study population according to PD-L1 expression. (A) The overall survival rate according to PD-L1 expression in TCs; (B) the overall survival rate according to PD-L1 expression in ICs. PD-L1, programmed death-ligand 1; TCs, tumor cells; ICs, tumor-infiltrating immune cells.

\section{Discussion}

In the population of the present study, the ratio of responders to preoperative therapy was higher in the high MLH1 expression group compared with that in the low MLH1 expression group. TC PD-L1 expression was more often detected in tumors with low MLH1 expression compared with high MLH1 expression.

These data suggest that the MLH1 protein expression level has potential as an indicator for treatment optimization and that determining tumor MLH1 expression may be beneficial for decision-making in esophageal cancer treatment. Specifically, patients with tumors exhibiting high MLH1 expression may benefit from systemic chemotherapy, whereas treatment other than chemotherapy should be considered for patients with tumors exhibiting low MLH1 expression.
The present study demonstrated that PD-L1 expression in TCs, but not ICs, was associated with MLH1 expression. This suggests that certain cancer cell-specific mechanisms may promote PD-L1 expression. Esophageal cancer cells with low MLH1 expression may exhibit more genomic mutations compared with those with high MLH1 expression due to an attenuated MMR system. Thus, an increase in tumor genomic mutations may prompt PD-L1 expression in TCs. The present study hypothesizes that there may be a mechanism by which mutation itself promotes PD-L1 expression or one in which a 'key' mutation switches on PD-L1 expression. Direct investigation of the correlation between mutational burden and PD-L1 expression is required.

MLH1 is a main component of MMR, and the loss of MLH1 function due to germline mutation or promoter 
methylation accounts for the majority of MMR deficiency. Immunohistochemical analysis of MLH1 protein expression is a simple and easy way to detect MMR deficiency, and its reliability has been investigated previously (24). In the present study, immunohistochemistry of MLH1 was performed as a reliable method to detect MMR deficiency.

The present study has several limitations, including the fact that it was a retrospective study conducted at a single institution, and the study population was comprised of patients who had not received PD-1/PD-L1 inhibition therapy. Accordingly, the results of the current study could not be compared with those of studies that examined the response to PD-1/PD-L1 inhibition therapy. Additional studies are required to validate PD-L1 and MLH1 expression in patients who have received PD-1/PD-L1 inhibition therapy.

In conclusion, MLH1 expression may be a predictive factor for the response to preoperative therapy in esophageal cancer, and esophageal cancer with low MLH1 expression level may have a mechanism that assists in promoting tumor PD-L1 expression.

\section{References}

1. Ando N, Kato H, Igaki H, Shinoda M, Ozawa S, Shimizu H, Nakamura T, Yabusaki H, Aoyama N, Kurita A, et al: A randomized trial comparing postoperative adjuvant chemotherapy with cisplatin and 5-fluorouracil versus preoperative chemotherapy for localized advanced squamous cell carcinoma of the thoracic esophagus (JCOG9907). Ann Surg Oncol 19: 68-74, 2012.

2. Cunningham D, Allum WH, Stenning SP, Thompson JN, Van de Velde CJ, Nicolson M, Scarffe JH, Lofts FJ, Falk SJ, Iveson TJ, et al: Perioperative chemotherapy versus surgery alone for resectable gastroesophageal cancer. N Engl J Med 355: 11-20, 2006.

3. van Hagen P, Hulshof MC, van Lanschot JJ, Steyerberg EW, van Berge Henegouwen MI, Wijnhoven BP, Richel DJ, Nieuwenhuijzen GA, Hospers GA, Bonenkamp JJ, et al: Preoperative chemoradiotherapy for esophageal or junctional cancer. $\mathrm{N}$ Engl $\mathrm{J}$ Med 366: 2074-2084, 2012.

4. Fujita H: History of lymphadenectomy for esophageal cancer and the future prospects for esophageal cancer surgery. Surg Today 45: 140-149, 2015.

5. Nakajima $\mathrm{M}$ and Kato H: Treatment options for esophageal squamous cell carcinoma. Expert Opin Pharmacother 14: 1345-1354, 2013.

6. Akutsu $\mathrm{Y}$ and Matsubara H: Chemoradiotherapy and surgery for T4 esophageal cancer in Japan. Surg Today 45: 1360-1365, 2015.

7. Topalian SL, Hodi FS, Brahmer JR, Gettinger SN, Smith DC, McDermott DF, Powderly JD, Carvajal RD, Sosman JA, Atkins MB, et al: Safety, activity, and immune correlates of anti-PD-1 antibody in cancer. N Engl J Med 366: 2443-2454, 2012.

8. Brahmer JR, Tykodi SS, Chow LQ, Hwu WJ, Topalian SL, Hwu P, Drake CG, Camacho LH, Kauh J, Odunsi K, et al: Safety and activity of anti-PD-L1 antibody in patients with advanced cancer. N Engl J Med 366: 2455-2465, 2012.
9. Kojima T, Hara H, Yamaguchi K, Hironaka S, Iwasa S, Kato K, Tsushima T, Yasui H, Ura T, Muro K, et al: Phase II study of nivolumab (ONO-4538/BMS-936558) in patients with esophageal cancer: Preliminary report of overall survival. J Clin Oncol 34 (Suppl 4S): abstr TPS175, 2016.

10. Le DT, Uram JN, Wang H, Bartlett BR, Kemberling H, Eyring AD, Skora AD, Luber BS, Azad NS, Laheru D, et al: PD-1 blockade in tumors with mismatch-repair deficiency. N Engl J Med 372: 2509-2520, 2015.

11. Carbognin L, Pilotto S, Milella M, Vaccaro V, Brunelli M, Caliò A, Cuppone F, Sperduti I, Giannarelli D, Chilosi M, et al: Differential activity of nivolumab, pembrolizumab and MPDL3280A according to the tumor expression of programmed death-ligand-1 (PD-L1): Sensitivity analysis of trials in melanoma, lung and genitourinary cancers. PLoS One 10: e0130142, 2015.

12. Hewish M,Lord CJ, Martin SA, Cunningham D and Ashworth A: Mismatch repair deficient colorectal cancer in the era of personalized treatment. Nat Rev Clin Oncol 7: 197-208, 2010.

13. Tzao C, Hsu HS, Sun GH, Lai HL, Wang YC, Tung HJ, Yu CP, Cheng YL and Lee SC: Promoter methylation of the hMLH1 gene and protein expression of human mutL homolog 1 and human mutS homolog 2 in resected esophageal squamous cell carcinoma. J Thorac Cardiovasc Surg 130: 1371, 2005.

14. Gryfe R, Kim H, Hsieh ET, Aronson MD, Holowaty EJ, Bull SB, Redston $\mathrm{M}$ and Gallinger S: Tumor microsatellite instability and clinical outcome in young patients with colorectal cancer. N Engl J Med 342: 69-77, 2000

15. Ward R, Meagher A, Tomlinson I, O'Connor T, Norrie M, Wu R and Hawkins N: Microsatellite instability and the clinicopathological features of sporadic colorectal cancer. Gut 48: 821-829, 2001.

16. Sargent DJ, Marsoni S, Monges G, Thibodeau SN, Labianca R, Hamilton SR, French AJ, Kabat B, Foster NR, Torri V, et al: Defective mismatch repair as a predictive marker for lack of efficacy of fluorouracil-based adjuvant therapy in colon cancer. J Clin Oncol 28: 3219-3226, 2010.

17. Popat S, Hubner R and Houlston RS: Systematic review of microsatellite instability and colorectal cancer prognosis. J Clin Oncol 23: 609-618, 2005.

18. Sobin LH, Gospodarowicz MK and Wittekind C: TNM classification of malignant tumours. Wiley, 2009.

19. Makino T, Yamasaki M, Miyata H, Yoshioka S, Takiguchi S, Fujiwara Y, Nakajima K, Nishida T, Mori M and Doki Y: p53 mutation status predicts pathological response to chemoradiotherapy in locally advanced esophageal cancer. Ann Surg Oncol 17: 804-811, 2010.

20. Japan Esophageal Society: Japanese Classification of Esophageal Cancer, tenth edition: part I. Esophagus 6: 1-25, 2009.

21. Japan Esophageal Society: Japanese classification of esophageal cancer, tenth edition: parts II and III. Esophagus 6: 71-94, 2009.

22. Kishi K, Doki Y, Yano M, Yasuda T, Fujiwara Y, Takiguchi S, Kim S, Higuchi I and Monden M: Reduced MLH1 expression after chemotherapy is an indicator for poor prognosis in esophageal cancers. Clin Cancer Res 9: 4368-4375, 2003.

23. Herbst RS, Soria JC, Kowanetz M, Fine GD, Hamid O, Gordon MS, Sosman JA, McDermott DF, Powderly JD, Gettinger SN, et al: Predictive correlates of response to the anti-PD-L1 antibody MPDL3280A in cancer patients. Nature 515: 563-567, 2014.

24. Lanza G, Gafa R, Maestri I, Santini A, Matteuzzi M and Cavazzini L: Immunohistochemical pattern of MLH1/MSH2 expression is related to clinical and pathological features in colorectal adenocarcinomas with microsatellite instability. Mod Pathol 15: 741-749, 2002. 